\title{
A New Entropy-based Intuitionistic Fuzzy Multi-attribute Decision Making Method
}

\author{
Lanping Li \\ Department of Basic Subjects, Hunan University of Finance and Economics, Changsha, China
}

Email address:

fanguobingmath@163.com

To cite this article:

Lanping Li. A New Entropy-based Intuitionistic Fuzzy Multi-attribute Decision Making Method. American Journal of Applied Mathematics. Vol. 4, No. 6, 2016, pp. 277-282. doi: 10.11648/j.ajam.20160406.13

Received: October 6, 2016; Accepted: October 14, 2016; Published: November 7, 2016

\begin{abstract}
The main task of this paper is to develop a new decision making method based on a novel entropy measure of intuitionistic fuzzy sets. First a novel intuitionistic fuzzy entropy is constructed, then based on this information measure, new weighting methods are proposed for the intuitionistic fuzzy decision making problems with the attribute weights are completely unknown or partly known. Further the intuitionistic fuzzy TOPSIS method is developed in this paper, and two examples are given to illustrate effectiveness and practicability of proposed method.
\end{abstract}

Keywords: Intuitionistic Fuzzy Number, Entropy, Multi-Attribute Decision Making, TOPSIS Method

\section{Introduction}

Because of the complexity and limitations of human understanding of the world, more and more management problems involve a lot of fuzzy concepts, such as, expected cost between 180 with 200 million, demand about 200 people. Therefore, since the fuzzy set was firstly proposed by Zadeh [1], fuzzy sets have been applied to various fields, especially the multiple attribute decision making problems based on fuzzy sets have been widely studied and applied to many field, such as supplier partner selection, military weapon system evaluation and selection of manufacturers [24]. Because of the complexity and the uncertainty of information of the actual management problem, in decisionmaking process decision makers often show some hesitation. In order to describe the hesitancy degree, Atanassov [5] proposed the concept of intuitionistic fuzzy sets. Intuitionistic fuzzy numbers can not only describe the general range of these fuzzy numbers, but also can describe the uncertainty of decision makers on the judgment of the decision makers. It also considers the degree of membership, non membership and hesitancy degree of three aspects of information, which can describe the fuzzy concept betwixt the more delicate describe the fuzzy nature of the objective world. It is the expansion and development of Zadeh fuzzy set theory [6]. In 1993, Gau and Buehrer [7] defined vague sets, and then Bustince and Burillo [8] pointed out that the notion of vague sets was the same with that of intuitionistic fuzzy set. In recent years, there are many intuitionistic fuzzy multiattribute decision making (MADM) methods are developed to deal with decision making problems [9-11].

Entropy is an important measure to describe the degree of fuzzy set and the degree of uncertainty. Fuzzy entropy has been widely applied to pattern recognition, image processing, clustering analysis and MADM problem [12-14]. The research on intuitionistic fuzzy entropy has been concerned and studied by some scholars. For example, Burillo and Bustince [15] introduced the intuitionistic fuzzy entropy measure for measuring fuzziness degree or uncertain information of intuitionistic fuzzy sets. Zhang and Jiang [16] defined a measure of intuitionistic fuzzy entropy by generalizing of the Deluca and Termini logarithmic fuzzy entropy; Ye [17] proposed two intuitionistic fuzzy entropy measures using two triangular functions; Verma and Sharma [18] defined an exponential intuitionistic fuzzy entropy measure by generalizing of the Pal and Pal's exponential fuzzy entropy. Wang [19] proposed an intuitionistic fuzzy entropy measure using a cotangent function.

In this paper, we will put forward a new intuitionistic fuzzy entropy measure, and then we will develop a new entropy-based intuitionistic fuzzy MADM method in which the weights information are complete unknown and partially known.

The organization of this paper is: In Section 2, the basic 
definitions and notations of intuitionistic fuzzy set are given. Section 3 constructs a new intuitionistic fuzzy information measure and proves that it is an entropy measure. Section 4 puts forward an intuitionistic fuzzy MADM method in which the weights of attribute are obtained according to the proposed intuitionistic fuzzy entropy measure. Two examples are provided in Section 5. Finally, conclusions are given in Section 6.

\section{Preliminaries}

Definition1 [20]. Let $X$ be a given universal set, the intuitionistic fuzzy set $A$ is defined as $A=\left\{<x_{i}, \mu_{A}\left(x_{i}\right), v_{A}\left(x_{i}\right)>\mid x_{i} \in X\right\}$, where the functions $\mu_{A}: X \mapsto[0,1]$ and $v_{A}: X \mapsto[0,1]$ are the membership degree and non-membership degree of $x_{i}$ respectively, and they satisfy $0 \leq \mu_{A}\left(x_{i}\right)+v_{A}\left(x_{i}\right) \leq 1$ for any $x_{i} \in X$. Further more, $\pi_{A}\left(x_{i}\right)=1-\mu_{A}\left(x_{i}\right)-v_{A}\left(x_{i}\right)$ is called the hesitancy degree of $x_{i}$. Conveniently, $\left\langle x_{i}, \mu_{A}\left(x_{i}\right), v_{A}\left(x_{i}\right)>\right.$ is called the intuitionistic fuzzy number, abbreviated as $\left(\mu_{A}\left(x_{i}\right), v_{A}\left(x_{i}\right)\right)$.

Definition2. Let $A=\left\{<x_{i}, \mu_{A}\left(x_{i}\right), v_{A}\left(x_{i}\right)>\mid x_{i} \in X\right\}$ and $B=\left\{<x_{i}, \mu_{B}\left(x_{i}\right), v_{B}\left(x_{i}\right)>\mid x_{i} \in X\right\}$ be two intuitionistic fuzzy sets, then the operation laws can be founded in [20]:

(1) $A \subseteq B$ iff $\mu_{A}\left(x_{i}\right) \leq \mu_{B}\left(x_{i}\right), v_{A}\left(x_{i}\right) \geq v_{B}\left(x_{i}\right), \forall x_{i} \in X$;

(2) $A=B$ iff $A \subseteq B$ and $B \subseteq A$;

(3) The complementary set $A^{C}$ of $A$ is $A^{C}=\left\{<x_{i}, v_{A}\left(x_{i}\right), \mu_{A}\left(x_{i}\right)>\mid x_{i} \in X\right\} ;$

(4) $A \preceq B$ called $A$ less fuzzy than $B$, that is, for $\forall x_{i} \in X$,

If $\mu_{B}\left(x_{i}\right) \leq v_{B}\left(x_{i}\right)$, then $\mu_{A}\left(x_{i}\right) \leq \mu_{B}\left(x_{i}\right), v_{A}\left(x_{i}\right) \geq v_{B}\left(x_{i}\right)$;

If $\mu_{B}\left(x_{i}\right) \geq v_{B}\left(x_{i}\right)$, then $\mu_{A}\left(x_{i}\right) \geq \mu_{B}\left(x_{i}\right), v_{A}\left(x_{i}\right) \leq v_{B}\left(x_{i}\right)$.

Definition 3[21]. Let $A=\left\{<x_{i}, \mu_{A}\left(x_{i}\right), v_{A}\left(x_{i}\right)>\mid x_{i} \in X\right\}$ and $B=\left\{<x_{i}, \mu_{B}\left(x_{i}\right), v_{B}\left(x_{i}\right)>\mid x_{i} \in X\right\}$ be two intuitionistic fuzzy set, $w_{i}$ is the weight of element $x_{i}$, then we can define the weighted Hamming distance measure between $A$ and $B$ as

$$
\begin{aligned}
d(A, B)= & \frac{1}{2} \sum_{i=1}^{n} w_{i}\left(\left|\mu_{A}\left(x_{i}\right)-\mu_{B}\left(x_{i}\right)\right|\right. \\
& \left.+\left|v_{A}\left(x_{i}\right)-v_{B}\left(x_{i}\right)\right|+\left|\pi_{A}\left(x_{i}\right)-\pi_{B}\left(x_{i}\right)\right|\right)
\end{aligned}
$$

The intuitionistic fuzzy entropy measure is given in Definition 4.

Definition 4 [15]. Let $\operatorname{IFS}(X)$ is the set of all intuitionistic fuzzy sets defined in $X$. Then A map $E: \operatorname{IFS}(X) \rightarrow[0,1]$ called the intuitionistic fuzzy entropy, if it satisfies the following four conditions:

(i) $E(A)=0$ if and only if $A$ is a crisp set;

(ii) $E(A)=1$ if and only if $\mu_{A}\left(x_{i}\right)=v_{A}\left(x_{i}\right), \forall x_{i} \in X$;

(iii) $E(A)=E\left(A^{C}\right)$; (iv) If $A \preceq B$, then $E(A) \leq E(B)$.

\section{A New Intuitionistic Fuzzy Entropy}

This section will first construct a new information measure and then prove that it is a entropy measure for intuitionistic set.

The new intuitionistic fuzzy information measure is constructed as follows:

$$
E(A)=\frac{1}{n} \sum_{i=1}^{n} \frac{1-\left(\mu_{A}\left(x_{i}\right)-v_{A}\left(x_{i}\right)\right)^{2}}{1+3\left(\mu_{A}\left(x_{i}\right)-v_{A}\left(x_{i}\right)\right)^{2}}
$$

Theorem. The measure given by Eq.(2) is an intuitionistic fuzzy entropy.

Proof. To prove the measure given by Eq.(2) is an intuitionistic fuzzy entropy, we only need to prove it satisfies the four cases (i)-(iv) in definition 4. Obviously, $0 \leq E(A) \leq 1$.

For the case (i). Let $A$ be a crisp set. That is, for $\forall x_{i} \in X$, $\mu_{A}\left(x_{i}\right)=0, v_{A}\left(x_{i}\right)=1$ or $\mu_{A}\left(x_{i}\right)=1, v_{A}\left(x_{i}\right)=0$.It is obvious that $E(A)=0$.

$$
\text { If } E(A)=0 \text {, that is } E(A)=\frac{1}{n} \sum_{i=1}^{n} \frac{1-\left(\mu_{A}\left(x_{i}\right)-v_{A}\left(x_{i}\right)\right)^{2}}{1+3\left(\mu_{A}\left(x_{i}\right)-v_{A}\left(x_{i}\right)\right)^{2}}=0,
$$

then for $\forall x_{i} \in X$, we have

$$
\sum_{i=1}^{n} \frac{1-\left(\mu_{A}\left(x_{i}\right)-v_{A}\left(x_{i}\right)\right)^{2}}{1+3\left(\mu_{A}\left(x_{i}\right)-v_{A}\left(x_{i}\right)\right)^{2}}=0,
$$

It is obvious that $1-\left(\mu_{A}\left(x_{i}\right)-v_{A}\left(x_{i}\right)\right)^{2}=0$, then we can conclude that $\mu_{A}\left(x_{i}\right)=0, v_{A}\left(x_{i}\right)=1$ or $\mu_{A}\left(x_{i}\right)=1, v_{A}\left(x_{i}\right)=0$. Therefore the set $A$ is a crisp set.

For the case (ii). If $\mu_{A}\left(x_{i}\right)=v_{A}\left(x_{i}\right), \forall x_{i} \in X$, then we can easily shown that $E(A)=1$ for the Eq. (2).

Now we suppose that $E(A)=1$, then for all $x_{i} \in X$, we have

$$
\frac{1-\left(\mu_{A}\left(x_{i}\right)-v_{A}\left(x_{i}\right)\right)^{2}}{1+3\left(\mu_{A}\left(x_{i}\right)-v_{A}\left(x_{i}\right)\right)^{2}}=1,
$$

Then we immediately obtain the conclusion $\mu_{A}\left(x_{i}\right)=v_{A}\left(x_{i}\right)$ for all $x_{i} \in X$.

For the case (iii). Because $A^{C}=\left\{<x_{i}, v_{A}\left(x_{i}\right), \mu_{A}\left(x_{i}\right)>\mid x_{i} \in X\right\}$,

we have

$$
\begin{aligned}
& E\left(A^{C}\right)=\frac{1}{n} \sum_{i=1}^{n} \frac{1-\left(\mu_{A^{c}}\left(x_{i}\right)-v_{A^{c}}\left(x_{i}\right)\right)^{2}}{1+3\left(\mu_{A^{C}}\left(x_{i}\right)-v_{A^{c}}\left(x_{i}\right)\right)^{2}} \\
& =\frac{1}{n} \sum_{i=1}^{n} \frac{1-\left(v_{A}\left(x_{i}\right)-\mu_{A}\left(x_{i}\right)\right)^{2}}{1+3\left(v_{A}\left(x_{i}\right)-\mu_{A}\left(x_{i}\right)\right)^{2}} \\
& =\frac{1}{n} \sum_{i=1}^{n} \frac{1-\left(\mu_{A}\left(x_{i}\right)-v_{A}\left(x_{i}\right)\right)^{2}}{1+3\left(\mu_{A}\left(x_{i}\right)-v_{A}\left(x_{i}\right)\right)^{2}}=E(A)
\end{aligned}
$$


For the case (iv). Construct the function

$$
f(x, y)=\frac{1-(x-y)^{2}}{1+3(x-y)^{2}},
$$

Where $x, y \in[0,1]$

We can easily derived the partial derivatives of $f(x, y)$ to $\mathrm{x}$ and to $\mathrm{y}$, respectively

$$
\begin{aligned}
& \frac{\partial f(x, y)}{\partial x}=\frac{-8(x-y)}{\left[1+3(x-y)^{2}\right]^{2}} \\
& \frac{\partial f(x, y)}{\partial y}=\frac{8(x-y)}{\left[1+3(x-y)^{2}\right]^{2}}
\end{aligned}
$$

When $x \leq y$, we have

$\frac{\partial f(x, y)}{\partial x} \geq 0$ and $\frac{\partial f(x, y)}{\partial x} \leq 0$,

That is to say, $f(x, y)$ is an increasing function with $\mathrm{x}$ and a decreasing function with $\mathrm{y}$. Then when the conditions $\mu_{B}\left(x_{i}\right) \leq v_{B}\left(x_{i}\right), \mu_{A}\left(x_{i}\right) \leq \mu_{B}\left(x_{i}\right)$ and $v_{A}\left(x_{i}\right) \geq v_{B}\left(x_{i}\right)$ are satisfied, we have $f\left(\mu_{A}\left(x_{i}\right), v_{A}\left(x_{i}\right)\right) \leq f\left(\mu_{B}\left(x_{i}\right), v_{B}\left(x_{i}\right)\right)$;

Similarly, it is easily proved that when $x \geq y$, we have $\frac{\partial f(x, y)}{\partial x} \leq 0$ and $\frac{\partial f(x, y)}{\partial x} \geq 0$, then $f(x, y)$ is a decreasing function with $\mathrm{x}$ and an increasing function with $\mathrm{y}$.

Thus when the conditions $\mu_{B}\left(x_{i}\right) \geq v_{B}\left(x_{i}\right)$, $\mu_{A}\left(x_{i}\right) \geq \mu_{B}\left(x_{i}\right)$ and $v_{A}\left(x_{i}\right) \leq v_{B}\left(x_{i}\right)$ satisfied, we have $f\left(\mu_{A}\left(x_{i}\right), v_{A}\left(x_{i}\right)\right) \leq f\left(\mu_{B}\left(x_{i}\right), v_{B}\left(x_{i}\right)\right)$.

Therefore, if $\quad A \preceq B \quad, \quad$ we have $\frac{1}{n} \sum_{i=1}^{n} f\left(\mu_{A}\left(x_{i}\right), v_{A}\left(x_{i}\right)\right) \leq \frac{1}{n} \sum_{i=1}^{n} f\left(\mu_{B}\left(x_{i}\right), v_{B}\left(x_{i}\right)\right)$,

Then $E(A) \leq E(B)$.

The theorem is proved.

\section{New Entropy-based Intuitionistic Fuzzy MADM Method}

This section will propose a new decision making method based on the new constructed intuitionistic fuzzy entropy.

Now we consider a MADM problem including $m$ noninferior alternatives $A_{i}(i=1,2, \ldots, m)$ and $n$ attributes $o_{j}$ $(j=1,2, \ldots, n)$. Here we let $A=\left\{A_{1}, A_{2}, \cdots, A_{m}\right\}$ be the set of these alternatives and $O=\left\{o_{1}, o_{2}, \cdots, o_{n}\right\}$ be the set of these attributes. The task of this section is to choose the best desirable alternative from $n$ non-inferior alternatives. Suppose that the evaluation values of alternatives $A_{i}$ on attributes $o_{j}$ are intuitionistic fuzzy numbers $\tilde{a}_{i j}=\left(\mu_{i j}, v_{i j}\right)$ $i=1,2, \ldots, m, j=1,2, \ldots, n$, Here $\mu_{i j}$ and $v_{i j}$ are the membership (satisfactory) degree and nonmembership (nonsatisfactory) degree of the alternative $A_{i}$ on the attribute $o_{j}$, and for any $i$ and $j, \mu_{i j}$ and $v_{i j}$ satisfy the following conditions:

$$
0 \leq \mu_{i j} \leq 1,0 \leq v_{i j} \leq 1 \text { and } 0 \leq \mu_{i j}+v_{i j} \leq 1 .
$$

Thus, a this intuitionistic fuzzy MADM problem can be expressed with the following decision matrix $\mathbf{D}=\left(\tilde{a}_{i j}\right)_{m \times n}$ as follows:

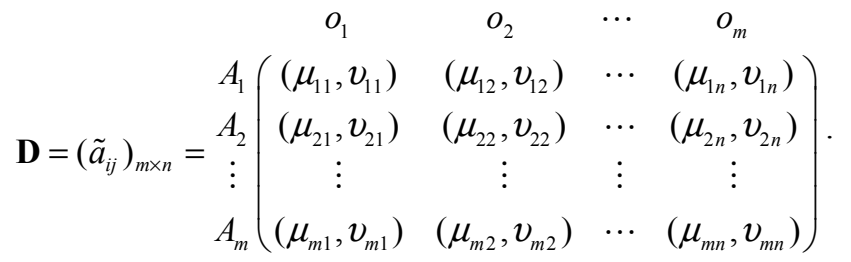

Let $\boldsymbol{w}=\left(w_{1}, w_{2}, \cdots, w_{n}\right)^{\mathrm{T}}$ be the weight vector of all attributes, where $0 \leq w_{j} \leq 1$ is the important degree of attributes $o_{j}(j=1,2, \cdots, n)$, and $\sum_{j=1}^{n} w_{j}=1$. The attribute weights information is usually unknown or partially known due to the limitation of time, knowledge etc. of decision makers in the decision making process. Therefore, the determination of attribute weights is an important issue which attracts great attention by many researchers [22-25]. This section will put forward two methods to determine the atstribute weights for the above-mentioned two cases.

\subsection{Weighting Method with Unkown Attribute Weights Information}

When the attribute weights are completely unknown, this section will propose a new entropy weighting method based on the new intuitionistic fuzzy entropy as follows:

Step 1. Calcalate the intuitionistic fuzzy entropy of $\tilde{a}_{i j}=\left(\mu_{i j}, v_{i j}\right)$ :

$$
E\left(\tilde{a}_{i j}\right)=\frac{1-\left(\mu_{i j}-v_{i j}\right)^{2}}{1+3\left(\mu_{i j}-v_{i j}\right)^{2}} .
$$

Step 2. The weight of the attribute $o_{j}$ is obtained as

$$
w_{j}=\frac{1-e_{j}}{n-\sum_{j=1}^{n} e_{j}}, \quad j=1,2, \ldots, n
$$

Here $e_{j}=\frac{1}{m} \sum_{i=1}^{m} E\left(\tilde{a}_{i j}\right)$.

\subsection{Weighting Method with Partially Known Attribute Weights Information}

In actual decision process, attribute weights information sometimes is partially known under intuitionistic fuzzy environment. To determine the weights, Xu [26] constructed an optimization model on the basis pf Chen and Tan's score function [27] to slove the optimal weights. Wu and Zhang [28] solved the attribute weights by establishing a 
programming model according to minimum entropy principle. Inspired by reference [28], this paper will use the new intuitionistic fuzzy entropy measure to solve the attribute weights by establishing a programming model as follows:

$$
\begin{array}{ll}
\min & E=\sum_{i=1}^{m} E\left(A_{i}\right)=\sum_{i=1}^{m} \sum_{j=1}^{n} w_{j} \frac{1-\left(\mu_{i j}-v_{i j}\right)^{2}}{1+3\left(\mu_{i j}-v_{i j}\right)^{2}} \\
\text { s.t. } \quad \sum_{j=1}^{n} w_{j}=1 & \quad \boldsymbol{w} \in \boldsymbol{H}
\end{array}
$$

Hence, the optimal attribute weights is the optimal solution $\boldsymbol{w}^{*}=\arg \min E$ of the programming model (8).

\subsection{The New Entropy-based Intuitionistic Fuzzy MADM Method}

This subsection will put forward a new intuitionistic fuzzy MADM method based on the above-mentioned work combining with the concept of TOPSIS. The calculation steps are given as follows:

Step 1. Calculate the attribute weights according to Eq.(6) and Eq.(7) when the attribute weights are completely unknown or partially known;

Step 2. Determine the positive ideal solution and negative ideal solution.

The positive ideal solution is defined as follows:

$$
A^{*}=\left(\left(\mu_{1}^{*}, v_{1}^{*}\right),\left(\mu_{2}^{*}, v_{2}^{*}\right), \cdots,\left(\mu_{n}^{*}, v_{n}^{*}\right)\right),
$$

where $\left(\mu_{j}^{*}, v_{j}^{*}\right)=(1,0)(j=1,2, \cdots, n)$.

The negative ideal solution is defined as follows:

$$
A^{-}=\left(\left(\mu_{1}^{-}, v_{1}^{-}\right),\left(\mu_{2}^{-}, v_{2}^{-}\right), \cdots,\left(\mu_{n}^{-}, v_{n}^{-}\right)\right),
$$

where $\left(\mu_{j}^{-}, v_{j}^{-}\right)=(0,1) \quad(j=1,2, \cdots, n)$.

Step 3. According to Definition 3, the weighted Hamming distance measures between alternative $A_{i}$ with positive and negative ideal solutions are respectively calculated as follows:

$$
\begin{aligned}
d\left(A_{i}, A^{*}\right) & =\frac{1}{2} \sum_{j=1}^{n} w_{j}\left(\left|\mu_{i j}-\mu_{j}^{*}\right|+\left|v_{i j}-v_{j}^{*}\right|+\left|\pi_{i j}-\pi_{j}^{*}\right|\right) \\
& =\frac{1}{2} \sum_{j=1}^{n} w_{j}\left(\left|1-\mu_{i j}\right|+\left|v_{i j}\right|+\left|1-\mu_{i j}-v_{i j}\right|\right) \\
d\left(A_{i}, A^{-}\right) & =\frac{1}{2} \sum_{j=1}^{n} w_{j}\left(\left|\mu_{i j}-\mu_{j}^{-}\right|+\left|v_{i j}-v_{j}^{-}\right|+\left|\pi_{i j}-\pi_{j}^{-}\right|\right) \\
& =\frac{1}{2} \sum_{j=1}^{n} w_{j}\left(\left|\mu_{i j}\right|+\left|1-v_{i j}\right|+\left|1-\mu_{i j}-v_{i j}\right|\right)
\end{aligned}
$$

Step 4. Calculate the relative closeness degree of each alternative.

The closeness degree $C_{i}$ is defined as:

$$
C_{i}=\frac{d\left(A_{i}, A^{-}\right)}{d\left(A_{i}, A^{-}\right)+d\left(A_{i}, A^{*}\right)}
$$

Step 5. Rank the alternatives according to $C_{i}$ in decreasing order. The best alternative is the closest to the positive ideal solution and the farthest to the negative ideal solution.

\section{Numerical Examples}

In order to illustrate the effectiveness and feasibility of the proposed MADM method, two examples are given as follows:

Example 1. (The case of complete unknown attributes weights information) This example is adopted from Herrera and Herrera-Viedma [29], Ye [30]. Suppose that a company wants to invest a large amount of money to some project. There are four parallel alternatives to be selected: a car company ( $A_{1}$ ), a food company ( $\left.A_{2}\right)$, a computer company ( $A_{3}$ ) and an arms company $\left(A_{4}\right)$. To choose the best desirable alternative, the decision maker consider the following evaluation attributes: the risk analysis $\left(o_{1}\right)$, the growth analysis $\left(\mathrm{O}_{2}\right)$ and the environmental impact analysis $\left(\mathrm{O}_{3}\right)$. Using statistical methods, we can obtain the satisfactory degree $\mu_{i j}$ and non-satisfactory degree $v_{i j}$ for the alternative $A_{i}$ satisfying the attributes $o_{j}$ respectively. The intuitionistic fuzzy decision matrix is illustrated in Table 1.

Table 1. Intuitionistic fuzzy decision matrix.

\begin{tabular}{llll}
\hline \multirow{2}{*}{ Alternative } & \multicolumn{3}{l}{ Evaluation attribute } \\
\cline { 2 - 4 } & \multicolumn{1}{l}{$\boldsymbol{o}_{1}$} & $\boldsymbol{o}_{2}$ & $\boldsymbol{O}_{3}$ \\
\hline$A_{1}$ & $(0.45,0.35)$ & $(0.50,0.30)$ & $(0.20,0.55)$ \\
$A_{2}$ & $(0.65,0.25)$ & $(0.65,0.25)$ & $(0.55,0.15)$ \\
$A_{3}$ & $(0.45,0.35)$ & $(0.55,0.35)$ & $(0.55,0.20)$ \\
$A_{4}$ & $(0.75,0.15)$ & $(0.65,0.20)$ & $(0.35,0.15)$ \\
\hline
\end{tabular}

The calculation steps are given as follows:

Step 1. According to the Eq. (7), the attribute weights vector is obtained as

$$
\boldsymbol{w}=\left(w_{1}, w_{2}, w_{3}\right)^{T}=(0.3384,0.3306,0.3309)^{T}
$$

Step 2. The positive ideal solution $A^{*}$ and negative ideal solution $A^{-}$are respectively

$$
\begin{gathered}
A^{*}=\left(\left(\mu_{1}^{*}, v_{1}^{*}\right),\left(\mu_{2}^{*}, v_{2}^{*}\right),\left(\mu_{3}^{*}, v_{3}^{*}\right)\right)=((1,0),(1,0),(1,0)) \\
A^{-}=\left(\left(\mu_{1}^{-}, v_{1}^{-}\right),\left(\mu_{2}^{-}, v_{2}^{-}\right),\left(\mu_{3}^{-}, v_{3}^{-}\right)\right)=((0,1),(0,1),(0,1))
\end{gathered}
$$

Step 3. The weighted Hamming distance measures of each alternative from positive and negative ideal solutions are calculated as 


$$
\begin{gathered}
d\left(A_{1}, A^{*}\right)=0.6162, d\left(A_{2}, A^{*}\right)=0.3831, \\
d\left(A_{3}, A^{*}\right)=0.4838, d\left(A_{4}, A^{*}\right)=0.4154 \\
d\left(A_{1}, A^{-}\right)=0.6003, d\left(A_{2}, A^{-}\right)=0.8169, \\
d\left(A_{3}, A^{-}\right)=0.6996, d\left(A_{4}, A^{-}\right)=0.8335
\end{gathered}
$$

Step 4. The relative closeness degrees are obtained as :

$$
\begin{aligned}
& C_{1}=0.4935, C_{2}=0.6808, \\
& C_{3}=0.5912, C_{4}=0.6674
\end{aligned}
$$

Therefore, the ranking order of all alternatives is $A_{2} \succ A_{4} \succ A_{3} \succ A_{1}$, and $A_{2}$ is the desirable alternative. The ranking order is in agreement with Ye [30].

Example 2. (The case of partially known attributes weights information) The example is adopted from $\mathrm{Li}$ [31], which considers an air-condition system selection problem. Suppose there are three air-condition systems $A_{1}, A_{2} A_{3}$ to be selected. The decision maker choses the following evaluation attributes: economical ( $\left.o_{1}\right)$, function $\left(o_{2}\right)$ and being operative $\left(\mathrm{O}_{3}\right)$. Using statistical methods, The satisfactory degree $\mu_{i j}$ and non-satisfactory degree $v_{i j}$ for the alternative $A_{i} \quad$ satisfying the attribute $o_{j}$ respectively. The intuitionistic fuzzy decision matrix is illustrated in Table 2.

Table 2. Intuitionistic fuzzy decision matrix.

\begin{tabular}{llll}
\hline \multirow{2}{*}{ Alternative } & \multicolumn{3}{l}{ Evaluation attribute } \\
\cline { 2 - 4 } & $\boldsymbol{o}_{1}$ & $\boldsymbol{o}_{2}$ & $\boldsymbol{o}_{3}$ \\
\hline$A_{1}$ & $(0.75,0.1)$ & $(0.6,0.25)$ & $(0.8,0.2)$ \\
$A_{2}$ & $(0.8,0.15)$ & $(0.68,0.2)$ & $(0.45,0.5)$ \\
$A_{3}$ & $(0.4,0.45)$ & $(0.75,0.05)$ & $(0.6,0.3)$ \\
\hline
\end{tabular}

Assume the weights information of the three attribute is partially known, and the weights satisfies the set

$$
\boldsymbol{H}=\left\{0.25 \leq w_{1} \leq 0.75,0.35 \leq w_{2} \leq 0.60,0.30 \leq w_{3} \leq 0.35\right\} .
$$

The calculation steps of the proposed MADM method is given as follows:

Step 1. According to the Eq. (8), we can establish the following programming model:

$$
\begin{aligned}
& \min E=0.6697 w_{1}+0.6654 w_{2}+0.8172 w_{3} \\
& \text { s.t. }\left\{\begin{array}{l}
0.25 \leq w_{1} \leq 0.75 \\
0.35 \leq w_{2} \leq 0.60 \\
0.30 \leq w_{3} \leq 0.35 \\
w_{1}+w_{2}+w_{3}=1
\end{array}\right.
\end{aligned}
$$

Then We the optimum attribute weight vector is solved by using Matlab software, and the optimal weight vector is obtained as $\boldsymbol{w}=(0.25,0.45,0.30)^{T}$.

Step 2. The positive ideal solution $A^{*}$ and negative ideal solution $A^{-}$are respectively

$$
\begin{gathered}
A^{*}=\left(\left(\mu_{1}^{*}, v_{1}^{*}\right),\left(\mu_{2}^{*}, v_{2}^{*}\right),\left(\mu_{3}^{*}, v_{3}^{*}\right)\right)=((1,0),(1,0),(1,0)) \\
A^{-}=\left(\left(\mu_{1}^{-}, v_{1}^{-}\right),\left(\mu_{2}^{-}, v_{2}^{-}\right),\left(\mu_{3}^{-}, v_{3}^{-}\right)\right)=((0,1),(0,1),(0,1))
\end{gathered}
$$

Step 3. The weighted Hamming distance measures of each alternative from positive and negative ideal solutions are calculated as

$$
\begin{aligned}
& d\left(A_{1}, A^{*}\right)=0.3025, d\left(A_{2}, A^{*}\right)=0.3590, \\
& d\left(A_{3}, A^{*}\right)=0.3825 \\
& d\left(A_{1}, A^{-}\right)=0.8025, d\left(A_{2}, A^{-}\right)=0.7225, \\
& d\left(A_{3}, A^{-}\right)=0.7750
\end{aligned}
$$

Step 4. The relative closeness degrees are obtained as

$$
C_{1}=0.7262, C_{2}=0.6681, C_{3}=0.6695
$$

Step 5. Based on $C_{i}$ values, the ranking result of the alternatives is $A_{1} \succ A_{3} \succ A_{2}$, and $A_{1}$ is the best desirable air-condition system. This reveals that the alternative is in agreement with the result in $\mathrm{Li}$ [31].

\section{Conclusion}

Intuitionistic fuzzy set is the extension of Zadeh's fuzzy set, and it can deal the decision with decision makers' hesitancy degree. This paper first construct a new intuitionistic fuzzy entropy measure and then puts forward a new decision making method for solving intuitionistic fuzzy MADM problem. Two weighting methods are proposed for the cases of weights are completely unknown and partially known. The new entropy measures can also be applied to the field of pattern recognition, image processing. The proposed intuitionistic fuzzy MADM method can also be applied to deal with other decision making problems, such as the project investment risk evaluation, material selection, robot selection and water quality evaluation.

\section{Acknowledgement}

This study is partially supported by Natural Science Foundation of Hunan Province (No. 2015JJ3030 and No. 2016JJ4012) and Foundation of Hunan Educational Committee (No.15C0228). The author also gratefully acknowledges the helpful comments and suggestions of the reviewers, which have improved the presentation.

\section{References}

[1] Zadeh L. A., 1965. Fuzzy sets. Information and Control, 8(3): 338-353.

[2] Dalman H., Güzel N., Sivri M., 2015. A fuzzy set-based approach to multi-objective multi-item solid transportation problem under uncertainty. International Journal of Fuzzy Systems, 18(4):716-729. 
[3] Lin P. C., Gu J. C., Yang M. T., 2014. Intelligent maintenance model for condition assessment of circuit breakers using fuzzy set theory and evidential reasoning. Iet Generation Transmission \& Distribution, 8(7):1244-1253.

[4] Ju H. C., 2014. Using the fuzzy set theory to developing an environmental impact assessment index for a thermal power plant. Quality \& Quantity, 48(2):673-680.

[5] Atanassov K. T., 1986. Intuitionistic fuzzy sets. Fuzzy Sets \& Systems, 20(1):87-96.

[6] Wang J. Q., Zhang H. Y., 2013. Multicriteria decision-making approach based on Atanassov's intuitionistic fuzzy sets with incomplete certain information on weights. IEEE Transactions on Fuzzy Systems, 21(3):510-515.

[7] Gau W. L., Buehrer D. J., 1993. Vague sets. Systems IEEE Transactions on systems, Man \& Cybernetics, 23(2):610-614.

[8] Bustince H., Burillo P., 1996. Vague sets are intuitionistic fuzzy sets. Fuzzy Sets and Systems, 79(3): 403-405.

[9] Xu Z., 2007. Some similarity measures of intuitionistic fuzzy sets and their applications to multiple attribute decision making. Fuzzy Optimization \& Decision Making, 6(2):109121.

[10] Joshi D., Kumar S., 2014. Intuitionistic fuzzy entropy and distance measure based TOPSIS method for multi-criteria decision making. Egyptian Informatics Journal, 15(2): 97-104.

[11] Liang X., Wei C., 2013. An Atanassov's intuitionistic fuzzy multi-attribute group decision making method based on entropy and similarity measure. International Journal of Machine Learning \& Cybernetics, 5(3): 435-444.

[12] Cheng H. D., Chen Y. H., Sun Y., 1999. A novel fuzzy entropy approach to image enhancement and thresholding. Signal Processing, 75(3): 277-301.

[13] Hsiao S. W., Chou J. R., 2006. A Gestalt-like perceptual measure for home page design using a fuzzy entropy approach. International Journal of Human-Computer Studies, 64(2): 137-156.

[14] Verma R., Sharma B. D., 2013. Exponential entropy on intuitionistic fuzzy sets. Kybernetika, 49(1): 114-127.

[15] Burillo P., Bustince H., 2001. Entropy on intuitionistic fuzzy sets and on interval-valued fuzzy sets. Fuzzy Sets and Systems, 118(3): 305-316.

[16] Zhang Q. S., Jiang S. Y., 2008. A note on information entropy measure for vague sets. Information Sciences, 178, (21): $4184-4191$

[17] Ye J., 2010.Two effective measures of intuitionistic fuzzy ertropy. Computing, 87(1/2): 55-62.
[18] Verma R., Sharma B. D., 2013. Exponential entropy on intuitionistic fuzzy sets, Kybernetika, 49(1): 114-127.

[19] Wang J. Q., Wang P., 2012. Intuitionistic linguistic fuzzy multi-criteria decision-making method based on intuitionistic fuzzy entropy, Control and Decision, 27(11): 1694-1698.

[20] Atanassov, K T., 1999. Intuitionistic Fuzzy Sets. New York: Physica-Verlag, Heidelberg.

[21] Li D. F., 2012. Intuitionistic Fuzzy Set Decision and Game Analysis Methodologies, Beijing: National Defense Industry Press.

[22] Xu Z., Zhang X., 2013. Hesitant fuzzy multi-attribute decision making based on TOPSIS with incomplete weight information. Knowledge-Based Systems, 52(6): 53-64.

[23] Biswas P., Pramanik S., Giri B. C., 2014. A new methodology for neutrosophic multi-attribute decision- making with unknown weight information. Neutrosophic Sets \& Systems, 3(3): $42-50$.

[24] Han Z. S., Liu P. D., 2011. A fuzzy multi-attribute decisionmaking method under risk with unknown attribute weights. Technological \& Economic Development of Economy, 17(2): 246-258.

[25] Wei G. W., 2010. Extension of TOPSIS method for 2-tuple linguistic multiple attribute group decision making with incomplete weight information. Knowledge \& Information Systems, 25(3): 623-634.

[26] Xu Z. S., 2007. Multi-person multi-attribute decision making models under intuitionistic fuzzy environment. Fuzzy Optimization Decision Making, 6(3): 221-236.

[27] Chen S. M., Tan J. M., 1994. Handing multicriteria fuzzy decision-making problems based vague set theory. Fuzzy Sets and Systems, 67(2): 163-172.

[28] Wu J. Z., Zhang Q., 2011. Multicriteria decision making method based on intuitionistic fuzzy weighted entropy. Expert Systems with Applications, 38(1), pp. 916-922.

[29] Herrera F., Herrera-Viedma E., 2000. Linguistic decision analysis: steps for solving decision problems under linguistic information. Fuzzy Sets \& Systems, 115(1): 67-82.

[30] Ye J., 2010. Fuzzy decision-making method based on the weighted correlation coefficient under intuitionistic fuzzy environment. European Journal of Operational Research, 205(1):202-204.

[31] Li D. F., 2005. Multiattribute decision making models and methods using intuitionistic fuzzy sets. Journal of Computer and System Sciences, 70(1): 73-85. 